\title{
Measuring Reciprocity in High Functioning Children and Adolescents with Autism Spectrum Disorders
}

\author{
Tineke Backer van Ommeren • Sander Begeer • \\ Anke M. Scheeren · Hans M. Koot
}

Published online: 20 July 2011

(C) The Author(s) 2011. This article is published with open access at Springerlink.com

\begin{abstract}
Few instruments have been developed that measure impairments in reciprocity, a defining feature of autism. We introduce a new test assessing the quality of reciprocal behaviour: the interactive drawing test (IDT). Children and adolescents $(n=49)$ with and without high functioning autism spectrum disorders (HFASD) were invited to collaborate with an experimenter in making a joint drawing. Within both groups the performance on collaborative reciprocity improved with age. However, compared to the control group, HFASD participants showed less collaborative and more basic reciprocal behaviour and preferred to draw their own objects. They were less tolerant of the experimenter's input as well. Performance on the IDT was independent of estimated verbal IQ. Reciprocal behaviour in self-initiated objects corresponded with more parental reported autistic traits, while reciprocal behaviour in other-initiated objects corresponded with less autistic traits. The findings of this study suggest that IDT is a promising instrument to assess reciprocity.
\end{abstract}

Keywords Autism · Reciprocity · Collaboration · Social interaction $\cdot$ Real life social skills

\section{Introduction}

Poor reciprocity is one of the defining features of an Autism Spectrum Disorder (ASD; APA 2000). However,

T. B. van Ommeren · S. Begeer $(\square) \cdot$ A. M. Scheeren H. M. Koot

Developmental Psychology, VU University Amsterdam, Van der Boechorststraat 1, 1081 BT Amsterdam, The Netherlands e-mail: S.Begeer@psy.vu.nl few studies have focused on the direct assessment of real life reciprocal behaviour by means of validated tests, in particular in normally intelligent, or high functioning children and adolescents with ASD (HFASD). Consequently, our knowledge of the nature and the development of a core feature of autism-the capacity to show reciprocal behaviour during real life, unstructured interactions-is limited. In the current study, reciprocal behaviour is analyzed in children and adolescents with HFASD with a new instrument that is specifically developed to examine reciprocity during a joint, unstructured social interaction: the Interactive Drawing Test (IDT).

The diagnostic criteria of an autistic disorder denote a lack of reciprocity as one of the required areas of impairment. The term reciprocity is not further explained in the DSM, but exemplified by anecdotal descriptions such as 'not actively participating in simple social play or games', 'preferring solitary activities', or 'involving others' in activities only as tools or "mechanical” aids' (APA 2000, p. 72). The ICD-10 (WHO 1992) is more forthcoming in their description of reciprocal impairments of individuals with autism, which are illustrated with "inadequate appreciation of socio-emotional cues, as shown by a lack of responses to other people's emotions and/or a lack of modulation of behaviour according to social context and, especially, a lack of socio-emotional reciprocity" Qualitative impairments in communication of individuals with autism are illustrated with "poor synchrony and lack of reciprocity in conversational interchange; lack of emotional response to other people's verbal and nonverbal overtures; impaired use of variations in cadence or emphasis to reflect communicative modulation; and a similar lack of accompanying gesture to provide emphasis or aid meaning in spoken communication" (WHO 1992, pp. 198-199). In addition to its inclusion in diagnostic 
criteria, the construct of reciprocity has a rich research background in economics and social psychology. Here it is usually defined by the reciprocity norm, which prescribes that we should help those who have helped us in the past and retaliate against those who have injured us, i.e., tit for tat (Komorita et al. 1992). More precisely defined, reciprocity includes mutual and symmetrical exchange between individuals while talking, working or playing together (Gernsbacher 2006), including finely timed turn taking and a steadily increasing dynamics as the interaction unfolds. Reciprocal behaviour is pivotal to the minute process of collaborative behaviour between individuals who perform activities to reach shared goals. Without equal participation and exchange with finely tuned turn taking, collaboration fails and does not lead to satisfactory results (Cole and Teboul 2004).

From early infancy on, young children show the motivation to engage in joint actions with others and share psychological states during dyadic interactions (Feldman and Greenbaum 1997; Trevarthen and Aitken 2001; Carpenter 2009). The ability to successfully collaborate with an other child develops from basic to more advanced levels during the course of early childhood. The first signs of parallel activity emerge at around 2 years of age, when groups of toddlers can be seen playing in each other's proximity and involved in the same type of activity. Their attention is centred on objects, but they operate separately and without much mutual exchange (e.g., playing along, rather than with another child). Gradually children develop the ability to behave in a complementary manner with a peer. Basic reciprocal behaviour can be observed when children start equal turn taking and object sharing (Eckerman et al. 1989; Warneken and Tomasello 2006). At 3 years of age, shared themes (e.g. building a sandcastle together) among playmates emerge (Howes 1988). Children also begin to understand that peers have rights as well as intentions to consider. During middle childhood more advanced, collaborative reciprocity emerges. By then children fully understand other's individual goals and intentions, as evidenced from the literature on Theory of Mind development (Yirmiya et al. 1998). Moreover, they have also gained the skills and motivation to share psychological states with one another (Tomasello et al. 2005). This sharing of intentions entails the infrastructure for basic and complex reciprocity. It enables children to play in more complicated ways, like building a small playhouse together or, indeed, making a joint drawing, with each child participating and attributing to achieve a common goal. Collaboration not only depends on the child's increasing cognitive skills but also on his or her emotional functioning (Perez and Gauvain 2005). The willingness to interact, to negotiate and the ability to emotionally deal with the input of another person are important facilitators for collaboration.
Various studies have investigated the ability of HFASD individuals to collaborate with adults. Preadolescent children with HFASD - in contrast to children with ASDhave been found to reciprocate adequately in structured test situations: they are able to collaborate successfully, e.g., on a Prisoner's Dilemma task (Sally and Hill 2006), show a good understanding of others' psychological states, and behave appropriately during social interactions, using acquired explicit social scripts or rules (Baron-Cohen et al. 1997; Bauminger and Kasari 1999; Begeer et al. 2003, 2010; Dahlgren and Trillingsgaard 1996; Happé 1995; Ponnet et al. 2004, 2005; Schatz and Hamdan-Allen 2007). Despite these assets, children with HFASD often fail to show appropriate reciprocal behaviour with adults and peers during unstructured real life interactions (Channon et al. 2001; Hadwin et al. 1997; Wimpory et al. 2007; Joseph and Tager-Flusberg 2004; Klin et al. 2007; Ozonoff and Miller 1995), respond less to bids for collaboration (Aldridge et al. 2000; Carpenter et al. 2001) and spend less time in social interactions with peers compared to typically developing children (Bauminger et al. 2003, 2008). The evidence for this impairment is primarily based on observations from children's daily life situations, rather than on direct assessments with psychological instruments.

In recent years, the Autism Diagnostic Observation Schedule; ADOS (Lord et al. 2000) has evolved ways of measuring reciprocity between an examiner and a child. The ADOS is a highly reliable and valid diagnostic instrument. It includes the observation of various activities in semi-structured situations, that allow the experimenter to observe social and reciprocal behaviour. The ADOS does assess the quality of contact with the experimenter in terms of frequency, pleasantness, and one sidedness. However, Reciprocal play and communication are evaluated based on the judgment of the examiner. With the IDT, we aim to target the quality or style of reciprocal behaviour based on the direct assessment of objectively specified responses.

In the current study we examined reciprocity during a test situation that is unstructured and unfamiliar for the child, by means of a new interactive testing procedure, the Interactive Drawing Test (IDT). During this test, which involves the production of a joint drawing, a child has the opportunity to show collaboration with an adult experimenter. To resemble the unstructured and unpredictable aspects of real life social interactions, the only instruction included a short comment ('we are going to draw together'), after which the experimenter and the child took turns in adding elements to the drawing. The topic of the activity was not mentioned, because we aimed to study whether collaborative drawing emerged spontaneously, rather than based on explicit instructions.

Basic reciprocity was measured by coding how often a drawing action of the child made a physical connection 
with the preceding drawing action of the experimenter. Collaborative reciprocity was coded when the child and the experimenter mutually drew meaningful objects, based on a shared underlying goal (e.g., when the child and the experimenter both add elements to the drawing of a tree). We also analysed who originally introduced an object or concept that then became a shared goal, and whether the child incorporated or dismissed the experimenter's additions in the drawing. Additional assessment of the correspondence of the IDT with standardized measures for the severity of social impairment was provided by examining the correlation of the IDT scores with the Social Responsiveness Scale, which quantifies the level of autistic severity using parent ratings (Constantino et al. 2003).

Individuals with HFASD were expected to show basic reciprocity to the same extent as typically developing controls, while showing diminished collaborative reciprocity, in particular in response to experimenter-initiated aspects of the drawing. We predicted that they would be less able to accept additions of the experimenter in their drawing, than the controls. Furthermore we expected more collaborative reciprocity on the IDT to correspond with a lower autism severity according to the SRS. Finally, based on their increased ability to understand others' psychological states and to employ explicit social scripts or rules adolescents were expected to show a better overall performance on the IDT than children.

\section{Method}

\section{Participants}

Participants were 49 children and adolescents (42 males, 7 females), including 24 participants with HFASD (3 females) and 25 typically developing comparison participants (4 females), group wise matched on age, gender and cognitive abilities, based on the Dutch version of the Peabody Picture Vocabulary Test-NL (Schlichting 2005; Dunn and Dunn 2004), which measures receptive vocabulary and correlates with overall intelligence (Bell et al. 2001). The HFASD participants were recruited from two psychiatric institutions specialised in treatment of autistic individuals in the Netherlands. The diagnostic classification of ASD was given by a psychiatrist according to established DSM-IV-TR-criteria and based on examination by multiple experienced clinicians (psychologists, psychiatrists and educationalists). The diagnostic process included anamneses, heteroanamneses, and psychiatric, neuropsychological and logo pedic examinations. Additional diagnostic information was obtained with the Social Responsiveness Scale (SRS, Constantino et al. 2003), a questionnaire for parents to quantify the level of autistic
Table 1 Age, PPVT, and SRS scores for HFASD and control participants: means, standard deviations, and range

\begin{tabular}{lll}
\hline & Controls $(\mathrm{n}=25)$ & HFASD $(\mathrm{n}=24)$ \\
\hline Age (in years) & $11.5(\mathrm{SD}=5.0)$ & $13.6(\mathrm{SD}=6.0)$ \\
& $6.7-19.7$ & $6.8-23.7$ \\
Peabody picture & $109(\mathrm{SD}=9.36)$ & $109(\mathrm{SD}=12.2)$ \\
vocabulary (PPVT) & $91-131$ & $96-145$ \\
Social Responsiveness & $21.9(\mathrm{SD}=8.50)$ & $92.5(\mathrm{SD}=27.69)$ \\
Scale (SRS) & $4-36$ & $54-159$ \\
\hline
\end{tabular}

severity of their child. This measure confirmed the clinical diagnoses (see Table 1 for sample characteristics).

\section{Material}

The material included a single sheet of drawing paper (A3), four different colour markers and a video camera, aimed at the drawing paper and the side of the participants.

\section{Procedure}

After informed consent was obtained from parents, the child was invited to participate. The test was administered in a quiet room in the child's school, and took place at the end of a 40-min session that included several other tests. The child was seated across the table from the experimenter. The drawing paper and colour markers were placed in the middle of the table. The experimenter told the child: 'We are going to draw together'. After both had chosen their own marker, the experimenter drew a single horizontal line and then shifted and rotated the paper towards the child. This shifting and rotating by the experimenter was continued during the IDT after each turn.

The experimenter received specific instructions what to draw and when. The first instruction was to draw a simple picture of a house. Besides this instruction, the experimenter, a trained psychologist, was expected to act as a neutral test experimenter, to respond to the child in a natural way, but without directive suggestions to the child regarding the drawing. The experimenter finished the house in five turns, allowing the child to make its own addition after each turn. The single lines of the house were finished regardless of the child's participation (see Fig. 2). Following the picture of the house, the experimenter started two other objects, one with a single bow and one with a wave figure. After introducing these elementary shapes, the experimenter was instructed to follow the child's drawing initiative without adding new elements (e.g., if the child made a face from the bow, by adding eyes and a mouth, the experimenter coloured in the irises).

After finishing the above described elements, the experimenter was specifically instructed to contribute to 
anything the child drew. Towards the end of the interaction, the experimenter was asked to make specific contributions to the child's drawing. First, the experimenter contributed in an appropriate or fitting way (e.g., adding apples to a tree that was drawn by the child). Second, the contribution of the experimenter became inappropriate (e.g., adding bottles to the child's tree). Third, the experimenter's contribution would change more radically an element of the child's drawing (e.g., a dark cloud, or bolt of lightning is drawn partially over the child's tree). After approximately $10 \mathrm{~min}$, the drawing phase was completed. The whole session was videotaped.

\section{Scoring}

Based on the analysis of the videotaped interaction, each drawn addition of the child and the experimenter was numbered. The total number of turns was registered in order to calculate the proportion of basic reciprocity, collaborative reciprocity and turn taking behaviour. Scores were analyzed in relation to the total number of turns, thus resulting in proportion scores for basic and collaborative reciprocity and 'no reciprocity' scores ranging from 0 to 1 . In each turn the addition of the child was analysed and given one score (basic or collaborative or 'no' reciprocity). In the rare event that in a turn a child did more than one addition, the 'best' addition was scored.

\section{No Reciprocity}

When the child did not add a meaningful element to the drawing of the experimenter, or did not draw in its close vicinity, the score was 0. (e.g. instead of joining the experimenter in drawing a house together, the child starts drawing a dinosaur further than $2 \mathrm{~cm}$ away from the house 'in progress' of the experimenter)

\section{Basic Reciprocity}

Whenever the child made a physical connection with or within two $\mathrm{cm}$ of the experimenter's preceding contribution, his or she scored one point for basic reciprocity. Furthermore, it was registered whether the connection was made in a drawing object initiated by the participant or the experimenter.

\section{Collaborative Reciprocity}

Each time the child joined the experimenter in a drawing with a mutual goal (e.g., the child and the experimenter both contribute to the drawing of a tree), the child scored one point for collaborative reciprocity. Again, we registered whether collaboration took place in a contribution initiated by the participant or the experimenter.

\section{Turn Taking Behaviour}

The total number of turn takings was counted and the number of times the child shifted and rotated the drawing paper back to the experimenter was registered. The child scored one point when both shifting and rotating were performed.

\section{Accepting the Experimenter's Input}

The response to the new, unfitting and radical changing contributions of the experimenter to elements of the child's drawing were scored as total acceptance (the child incorporates the addition, e.g., in response to the experimenter drawing wheels under the child's fish, the child adds a steering wheel in the fish) or no acceptance (the child dismisses the addition, ignores it by drawing elsewhere or gets angry or upset). Responses were analysed separately for the appropriate, inappropriate and radical changing additions of the experimenter.

Interrater reliability, based on two blind ratings of scores of all participants was excellent, with Cronbach's alphas ranging from .94 (basic reciprocity) to .97 (collaborative reciprocity). An elaborate scoring system can be obtained from the corresponding author.

\section{Social Responsiveness Scale}

The Social Responsiveness Scale (SRS) was used to index quantitative autistic traits in all participants. The SRS is a 65-item parent questionnaire which assesses social interactions, relationships, and communication skills. Studies using the SRS report high discriminant validity, differentiating well between typically developing, at-risk, and autism populations (Constantino et al. 2003).

\section{Results}

\section{Basic Reciprocity}

Repeated measures Anova for basic reciprocal behaviour with Group (HFASD vs. Comparisons) and Age (two age groups, denoted as children [<age 10 years; $\mathrm{n}=28$, including 13 children with HFASD and 15 children with TD] and adolescents [ $\geq$ age 16 years; $n=21$, including 11 children with HFASD and 10 children with TD]) as between-subjects factors and Initiative (child vs. experimenter) as within-subjects factor showed main effects for Group, $F_{(1,45)}=5.46, p=.02, d=.67$, and Initiative, $F_{(1,45)}=6.33, p=.02, d=.32$, but not for Age. Unexpectedly, the HFASD group used more basic reciprocity than the comparison group (i.e., they made more physical 
Table 2 Basic and collaborative reciprocity, means and standard deviations

\begin{tabular}{|c|c|c|c|c|c|c|c|}
\hline & \multirow[t]{2}{*}{ Initiative } & \multicolumn{3}{|l|}{ HFASD } & \multicolumn{3}{|l|}{ Controls } \\
\hline & & Child & Adolescent & Total & Child & Adolescent & Total \\
\hline \multirow[t]{3}{*}{ Basic reciprocity } & Participant & $.13(.11)$ & $.09(.09)$ & $.11(.10)$ & $.02(.03)$ & $.01(.02)$ & $.02(.03)$ \\
\hline & Experimenter & $.11(.10)$ & $.08(.10)$ & $.10(.10)$ & $.12(.12)$ & $.08(.10)$ & $.10(.10)$ \\
\hline & Total & $.24(.17)$ & $.18(.16)$ & $.21(.17)$ & $.14(.12)$ & $.10(.07)$ & $.12(.10)$ \\
\hline \multirow[t]{3}{*}{ Collaborative reciprocity } & Participant & $.25(.19)$ & $.41(.16)$ & $.33(.19)$ & $.24(.15)$ & $.23(.15)$ & $.24(.15)$ \\
\hline & Experimenter & $.12(.09)$ & $.23(.19)$ & $.17(.15)$ & $.34(.14)$ & $.56(.22)$ & $.43(.21)$ \\
\hline & Total & $.38(.23)$ & $.64(.22)$ & $.50(.26)$ & $.58(.20)$ & $.79(.12)$ & $.66(.20)$ \\
\hline
\end{tabular}

connections with the experimenter's drawing), while all participants tended to show more basic reciprocity in the experimenter-initiated elements of the drawing than in the child-initiated elements. A significant Group X Initiative interaction, $F_{(1,45)}=10.45, p=.01$, emanated from a higher number of basic reciprocal contributions in the HFASD than in the comparison group on elements of the drawing they had initiated themselves, $F_{(1,46)}=17.92$, $p<.001, d=1.21$. No group differences were found with regard to objects initiated by the experimenter (Table 2).

\section{Collaborative Reciprocity}

Repeated measures Anova for collaborative reciprocity with Group and Age as between-subjects factors and Initiative as within-subjects factor showed main effects of Group, $F_{(1,45)}=9.44, p<.01, d=.87$, and Age, $F_{(1,45)}=$ 17.37, $p=.001, d=1.06$. As expected, individuals with
HFASD showed less collaborative reciprocity than the comparison group, and younger children from both samples showed less collaborative reciprocity than adolescents (see Table 2).

An interaction effect for Group $\mathrm{X}$ Initiative, $F_{(1,45)}=$ $24.68, p<.001$, was due to contrasting group effects in the participants or experimenter initiated drawings. HFASD participants revealed a higher level of collaborative reciprocity based on their own than on the experimenter's initiative, $F_{(1,47)}=24.58, p=.001, d=1.29$. The comparison group showed a reverse pattern: they executed a near significant higher level of collaborative reciprocity when the experimenter took the initiative rather than when they initiated elements themselves $F_{(1,47)}=3.49, p=.06$, $d=.49$ (see Fig. 1).

A near significant interaction for Group X Age X Initiative, $F_{(1,45)}=3.63, p=.06$, was further analysed by testing the Age $\mathrm{X}$ Initiative interactions within both
Fig. 1 Proportion of collaborative engagement (The number of collaborative engagement contributions was calculated in relation to the total number of turns per child, resulting in proportion scores ranging from 0 to 1 ) based on participant or experimenter initiated elements of the drawing as a function of Group and Age

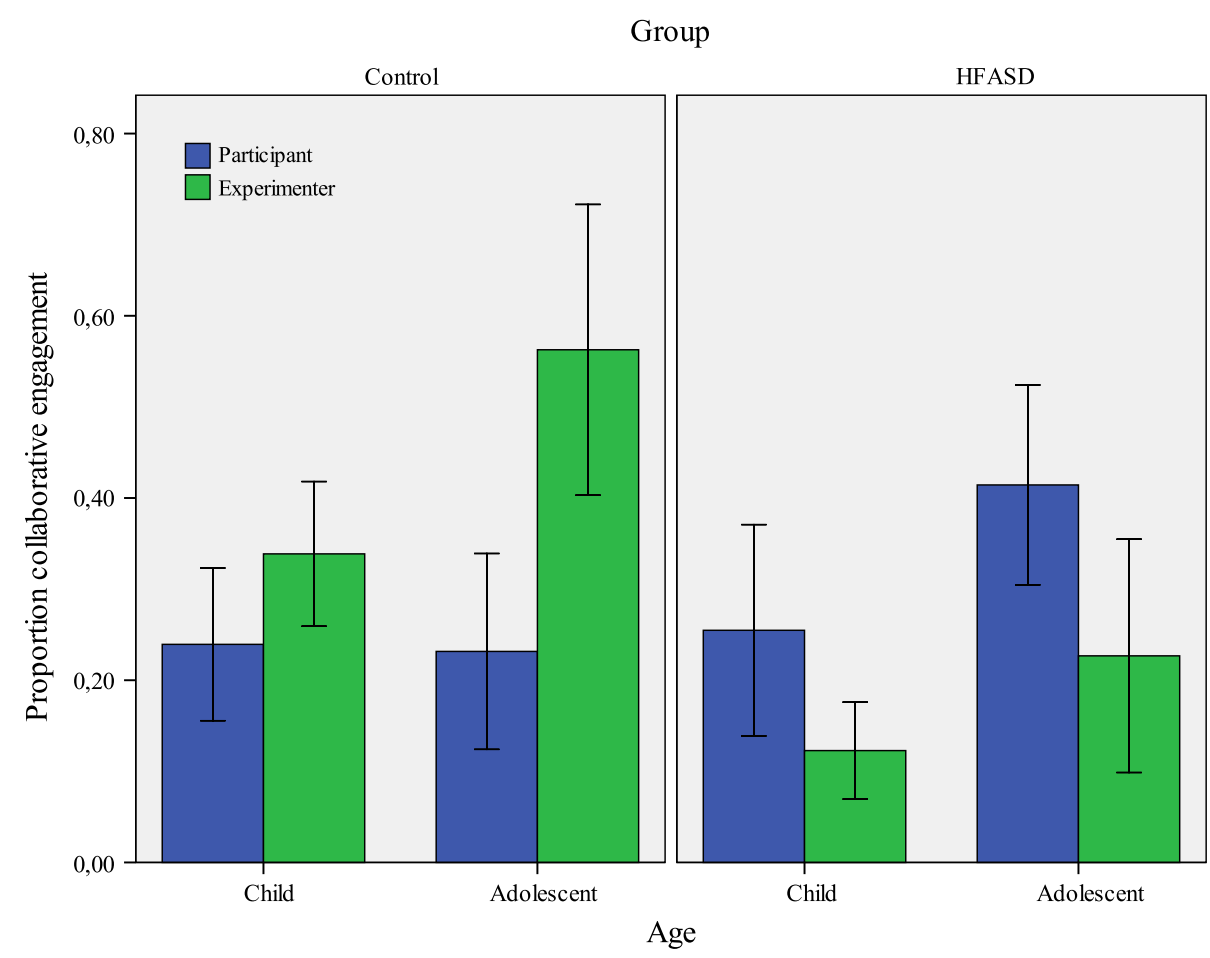


Groups. The simple effect of Age $\mathrm{X}$ Initiative was near significant in the comparison group, $F_{(1,23)}=4.03$, $p=.06$, but not in the HFASD group. When responding to an initiative of the experimenter, typically developing adolescents showed more collaborative reciprocity than typically developing children, $F_{(1,23)}=9.42, \quad p<.01$, $d=1.25$. Based on their own initiative, no age effects were found. The HFASD group showed contrasting age effects. On their own initiative, adolescents with HFASD collaborated more than children with HFASD, $F_{(1,22)}=4.71, \quad p<.05, \quad d=.89$. However, when responding to the experimenter's initiative, no age effects were found. In short, the older typically developing participants increasingly collaborated in experimenter-initiated elements of the drawing, while the older HFASD participants increasingly collaborated in their self-initiated elements of the drawing.

\section{Turn Taking Behaviour}

No differences were found in the number of turns taken by individuals from the HFASD $(\mathrm{M}=21.54, \mathrm{SD}=8.09)$ or comparison groups $(\mathrm{M}=27.54, \mathrm{SD}=15.38)$, but the children from both groups $(\mathrm{M}=28.69, \mathrm{SD}=14.93)$ took more turns than adolescents $(\mathrm{M}=19.10, \mathrm{SD}=5.03)$, $F_{(1,46)}=7.98, p<.01, d=.80$.

The percentage of the total number of turns where participants shifted and rotated the drawing paper back to the experimenter was lower in HFASD $(\mathrm{M}=30.58$, $\mathrm{SD}=34.10)$ than comparisons $(\mathrm{M}=66.25, \mathrm{SD}=33.90)$, $F_{(1,33)}=10.26, p<.01, d=1.06$, and in children from both groups $(\mathrm{M}=32.81, \mathrm{SD}=36.81)$ than adolescents $(\mathrm{M}=74.47, \quad \mathrm{SD}=24.64), \quad F_{(1,33)}=16.54, \quad p<.001$, $d=1.34$.

\section{Accepting the Experimenter's Input}

Typically developing children and adolescents accepted the appropriate additions of the experimenter in their drawing in all cases (e.g., after the experimenter added eyes to the head of a child's little doll figure, the child added a mouth). The HFASD children were less accepting (only $62 \%$ of the cases) than comparison children $(100 \%), \chi^{2}(1)=7.45$, $p<.01, d=.54$, but HFASD adolescents fully accepted experimenter's additions. Typically developing participants (both children and adolescents) also accepted the experimenter's input when it was inappropriate in all cases (e.g., after the experimenter added a face underneath a motorcar, the child transformed the motorcar into a hat), while HFASD participants only did so in $70 \%$ of the cases, $\chi^{2}(1)=8.34, p<.01, d=.46$. No group differences emerged with respect to the radical changing additions (e.g., the experimenter drew a thunderbolt into the child's tree), but adolescents (93\%) were generally more accepting than children $(61 \%), \chi^{2}(1)=4.73, p<.05, d=.35$.

Correlation of the IDT with Verbal IQ, Age, and Autism Severity

No significant correlations were found between any of the measures of the IDT and the estimated verbal IQ, giving rise to the assumption that the reciprocal behaviour as measured with the IDT is independent of cognitive abilities. Age correlated positively with the collaborative reciprocity scores based on the child's initiative, $r(49)=.34$, $p<.05, d=.72$, and with the frequency of shifting and rotated the drawing paper back to the experimenter $r(35)=.52, p<.005, d=1.21$.

The severity of the autistic impairment, based on parent reported levels of social impairment in 41 of the 49 children, as measured with the SRS (Constantino et al. 2003), showed positive correlations with the basic reciprocity scores in participant's own initiative, controlling for age, $r(35)=.47, p<.005, d=1.06$. This indicated that the presence of more autistic traits correspond with a higher tendency to show reciprocity on a basic level within selfinitiated elements of the drawing. A negative correlation was found between the SRS and the collaborative reciprocity scores based on the experimenter's initiative, $r(35)=-.54, p<.005, d=1.28$, indicating that the presence of less autistic traits corresponds with more collaborative reciprocity following the experimenter's initiative. The acceptance of radical changing experimenter input was also negatively correlated with the SRS scores, $r(32)=-.40, p<.05, d=.87$.

\section{Discussion}

The purpose of this study was to measure reciprocity in children and adolescents with and without HFASD. As expected, elementary social skills such as the amount and time of turn taking, contributing to a drawing and sharing a piece of paper were found in all participants with HFASD. Moreover, participants with HFASD showed even more basic reciprocal responses than typically developing children. They were more likely to draw in the vicinity of the experimenter's contribution, without attempting to contribute meaningful elements to the drawing. In contrast, HFASD participants showed less collaborative reciprocity than their typically developing peers. They were less inclined to join the experimenter in the construction of meaningful objects in the drawing. These findings are in line with recent research on helping and cooperation in HFASD children (Colombi et al. 2009; Liebal et al. 2008), which revealed HFASD children to be able and willing to 
help others, but often failing to perform full-fledged collaboration on a more general, abstract level. Weak coherence and a tendency to focus on details in children with ASD (Booth et al. 2003; Happé and Frith 2006) could be an explanation for this specific difference between groups.

The extent to which participants showed collaborative reciprocity was influenced by age and self-other orientation. While adolescents from both groups showed more collaborative reciprocity than children, opposing age effects were found when the initiator of the drawing interactions was taken into account. Children with HFASD, in contrast to the typically developing children, increased their collaborative reciprocity with age, but only when they initiated aspects of the drawing themselves (e.g., they accepted that the experimenter joined them in the drawing of a tree that they had started). In contrast, the comparison but not the HFASD group increased their collaborative efforts in experimenter initiated aspects of the drawing (e.g., they joined in drawing the experimenter's tree). These findings indicate that there is no absence of reciprocity in HFASD, in fact there seems to be a development of these skills - though longitudinal studies should confirm this. Rather, it seems important that collaborative reciprocity occurs under the conditions created by the HFASD participants themselves.

When critically interpreting the above findings, one might ask whether accepting another person's input in one's own drawing should be denoted as collaborative reciprocity. Is this behaviour truly reciprocal and therefore a mutual and symmetrical exchange between experimenter and child or is the child just constructing a drawing and passively accepting the experimenter's input? The current data may not allow for a decisive answer to these questions, but they do suggest that the proposed reciprocity impairments in autism occur mainly when a child has to adjust to the initiatives of another person. When the autistic individual is allowed to govern the situation, limitations in reciprocity may be less apparent as was the case in the current study.

In addition to the direct measures of reciprocity, limited turn taking behaviour confirms the suggested impaired reciprocal behaviour in HFASD. The experimenter pushed and rotated the paper back to the child after finishing each turn, but in return, individuals with HFASD showed less adequate turn taking behaviour than comparison children. Age was of influence on this behaviour in both groups: children rotated the paper less than adolescents. The lower frequency of rotating the paper suggests poorer perspective taking skills in the HFASD participants. The age effects confirm that this observation may be used to provide an additional non-verbal measure of reciprocity.

HFASD individuals were also remarkably less accepting of the experimenter's new additions to their drawing.
While typically developing children fully accepted all appropriate and unfitting additions, children with HFASD did not accept these in about a third of the cases. The tendency to refrain from accepting experimenter's additions puts the similar group levels of collaborative reciprocity based on the HFASD participants' initiative in a different perspective. These results reflect a tendency to refrain from collaborating in experimenter's initiatives rather than a tendency to welcome the experimenter to join the participant in his or her own initiative. Their reciprocity style may be characterized by unequally allowing others to determine the goal of an initiative, rather than by a lower level of mutual exchange per se.

One of the explanations for the tendency of HFASD participants to show more basic reciprocity, could be their inability to spontaneously act or switch their action pattern based on an unexpected or strange contribution of their drawing partner (Joseph and Tager-Flusberg 2004; Kleinhans et al. 2005). Flexibility of thought and behaviour is needed to adjust to the continual changing drawing elements. It is easier and quicker to reciprocate on a basic level (drawing in the vicinity of the experimenters additions) than on a more complicated collaborative level (requiring to figure out experimenter's drawing intentions). However, it should be noted that, like typically developing children, the HFASD participants did show more collaborative than basic reciprocity. Therefore, it can be concluded that they do not lack the flexibility for collaboration. The most explicit difference with the controls was their preference for collaborating based on their own initiative. By refraining to follow the experimenter initiative, the HFASD participants stay in control of the drawing actions and again do not need to switch their perspective to monitor the goals that the experimenter might be pursuing. The current findings are in line with previously found difficulties of HFASD participants in understanding other's intentions (Carpenter et al. 2001; Castelli 2006; Russell and Hill 2001; Tomasello et al. 2005). However, they also provide a useful addition to the literature on Theory of Mind. In particular, high functioning adolescents and adults with ASD pass Theory of Mind tasks at various levels of complexity (Bowler 1992; Dahlgren and Trillingsgaard 1996; Senju et al. 2009). Moreover, they seem to be able to take other people's perspectives into account during structured interactions (Begeer et al. 2008, 2010), or when adequately motivated (Begeer et al. 2003). However, in the unstructured IDT, HFASD participants responded poorly to the experimenter's input, especially when this input was inappropriate. The inclination to collaborate in their own initiative could be explained as a way to avoid confrontation with unexpected intentions of the experimenter, but could also be related to a lack of motivation to share goals. A more rigorous examination of the relationship between 
results on ToM tests and the IDT will be the focus of a follow up study.

A better performance on the IDT corresponded with less severe social impairments. Intelligence did not influence the IDT scores. Furthermore we found that levels of reciprocity correlated with matching SRS scores: i.e. more 'basic reciprocity in own initiative' correlated with higher SRS scores and 'collaborative reciprocity in other's initiative' correlated with lower SRS scores. These levels can be seen as opposite poles of involvement: 'self' orientated interactions without real involvement on a basic level versus 'other' orientated joining in full-fledged collaboration. Optimal reciprocity entails both the ability to join in with actions of others and the ability to accept and invite input of others. HFASD individuals more often fail to accomplish optimal reciprocity. In time, the level of reciprocity measured with the IDT may be used as indication of the severity of autistic impairments.

The current study has several limitations. First of all, the sample size was small, and age effects were not based on longitudinal analyses. Moreover, during the IDT the child interacts with a single adult opponent, while real life situations often require children to interact with several peers simultaneously. It is difficult to capture those types of situations in a standardized manner. In contrast with real life there also was an absence of failure or rejection (every input of the child was accepted). Dealing with rejection can be a challenge for children with ASD. Furthermore, real life collaboration often entails verbal negotiation in order to establish a mutual goal. The ability to establish meaningful eye contact and the degree in which participants enjoyed the drawing game were not measured, but could have influenced collaboration. In our follow up study we assess both aspects. The IDT only dealt with accepting each other's goal or establishing a tacit mutual concept without verbal negotiation and resembled only a specific kind of situation. It's independence of verbal ability makes the test appropriate for administration in lower functioning children with ASD. However, to interpret performances on the IDT of these children needs further study.

The IDT provides useful clinical information to parents and other caretakers on why, how and to what degree their child is able to reciprocate with peers and siblings, in particular when we obtain norm scores and can show individual differences within a HFASD sample. The amount of basic and collaborative reciprocity, positive or negative results on turn taking behaviour and accepting or rejecting inputs and their correspondence with specific autistic impairments provide concrete clues for further treatment and training. For example, if the performance on the IDT reveals that the child has collaborative skills but refrains from collaborating based on other people's initiative, this could be a specific topic for the training.

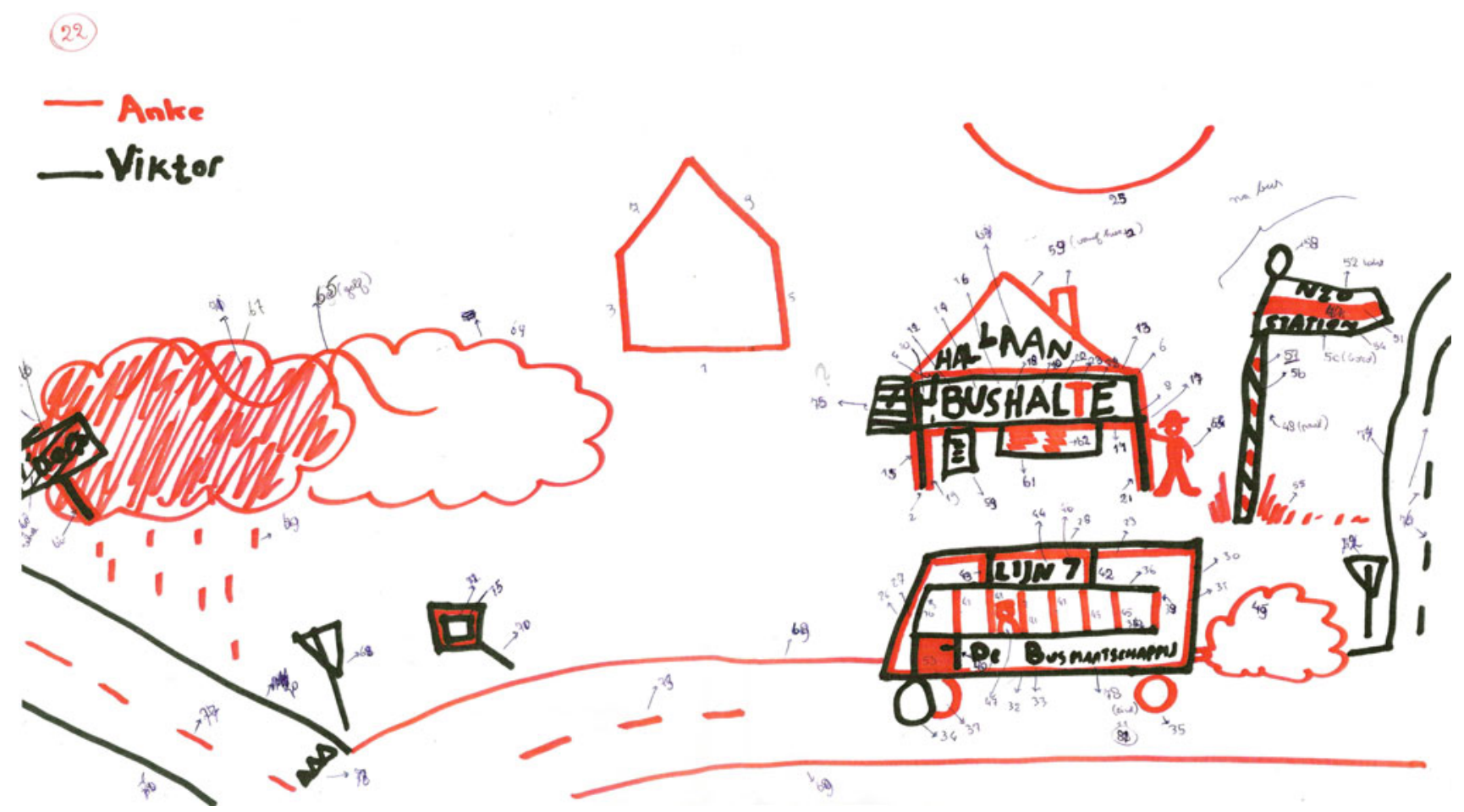

Fig. 2 Example of a drawing by a HFASD participant (see "Appendix" for an explanation of the exchange) 
The ability to specifically target these behaviours allows for further theorizing about one of the core impairments of individuals with autism: their incapacity to respond appropriately during the many unstructured interactions they encounter throughout their lives. Being able to administer this test in $10 \mathrm{~min}$, using only a piece of paper and four color markers, is an important asset of the current procedure. Designing instruments to target these specific impairments should be an important aim for future studies. Further testing the collaborative reciprocity of HFASD may reveal more specific clues for treatment as well as for training HFASD individuals to improve their style of collaboration. The IDT aids to these goals and is applicable in its current form, but in need of further validation.

Acknowledgments We wish to thank all the children and parents who participated in the study, and all the graduate students who helped with the data collection, in particular Nathalie Viskaal.

Open Access This article is distributed under the terms of the Creative Commons Attribution Noncommercial License which permits any noncommercial use, distribution, and reproduction in any medium, provided the original author(s) and source are credited.

\section{Appendix}

The drawing (Fig. 2) of the experimenter (Anke) and a child with ASD (Viktor) is an example of the limited reciprocal behaviour that we found in the ASD group. After the first line of the experimenter (no 1) the child responded by drawing its own line (no 2) far away from the first line of the experimenter. This is scored as no reciprocity. The child persisted in drawing his own 'bus stop' in the next turns. However, when the experimenter joined the child in drawing this 'bus stop' (no 11), collaborative reciprocal behaviour emerged in the child's object, until turn no 24 . Then the experimenter again 'invited' the child to engage in her drawing by making the 'bow' (no 25), however, Viktor responded by starting his own bus (no 26).

\section{References}

Aldridge, M. A., Stone, K. R., Sweeney, M. H., \& Bower, T. G. R. (2000). Preverbal children with autism understand the intentions of others. Developmental Science, 3, 294-301.

American Psychiatric Association. (2000). Diagnostic and statistical manual of mental disorders (4th ed.). Washington D.C.: Author.

Baron-Cohen, S., Jolliffe, T., Mortimore, C., \& Robertson, M. (1997). Another advanced test of theory of mind: Evidence from very high functioning adults with autism or asperger syndrome. Journal of Child Psychology and Psychiatry, 38, 813-822.

Bauminger, N., \& Kasari, C. (1999). Brief report: Theory of mind in high-functioning children with autism. Journal of Autism and Developmental Disorders, 29, 81-86.
Bauminger, N., Shulman, C., \& Agam, G. (2003). Peer interaction and loneliness in high-functioning children with autism. Journal of Autism and Developmental Disorders, 33, 489-507.

Bauminger, N., Solomon, S., Aviezer, A., Heung, K., Gazit, L., Brown, J., et al. (2008). Children with autism and their friends: A multidimensional study of friendship in high-functioning autism spectrum disorder. Journal of Abnormal Child Psychology, 36, $135-150$

Begeer, S., Koot, H. M., Rieffe, C., Meerum Terwogt, M., \& Stegge, H. (2008). Emotional competence in children with autism: Diagnostic criteria and empirical evidence. Developmental Review, 28, 342-369.

Begeer, S., Malle, B. F., Nieuwland, M., \& Keysar, B. (2010). Using theory of mind to represent and take part in social interactions: Comparing individuals with high-functioning autism and typically developing controls. European Journal of Child Development, 7, 104-122.

Begeer, S., Rieffe, C., Meerum Terwogt, M., \& Stockmann, L. (2003). Theory of mind-based action in high-functioning children from the autism spectrum. Journal of Autism and Developmental Disorders, 33, 479-487.

Bell, N. L., Lassiter, K. S., Matthews, T. D., \& Hutchinson, M. B. (2001). Comparison of the peabody picture vocabulary test-third edition and wechsler adult intelligence scale-third edition with university students. Journal of Clinical Psychology, 57, 417-422.

Booth, R., Charlton, R., Hughes, C., \& Happé, F. (2003). Disentangling weak coherence and executive dysfunction: Planning drawing in autism and attention-deficit/hyperactivity disorder. The Royal Society, 358, 387-392.

Bowler, D. M. (1992). "Theory of mind" in Asperger's syndrome. Journal of Child Psychology and Psychiatry, 33, 877-893.

Carpenter, M. (2009). Just how joint is joint action in infancy? Topics in Cognitive Science, 1, 380-392.

Carpenter, M., Pennington, B., \& Rogers, S. (2001). Understanding of others' intentions in children with autism. Journal of Autism and Developmental Disorders, 31, 589-599.

Castelli, F. (2006). The Valley Task: Understanding intention from goal-directed motion in typical development and autism. The British Journal of Developmental Psychology, 24, 655-668.

Channon, S., Charman, T., Heap, J., Crawford, S., \& Rios, P. (2001). Real-life-type problem-solving in Asperger's syndrome. Journal of Autism and Developmental Disorders, 31, 461-469.

Cole, T., \& Teboul, J. C. B. (2004). Non-zero-sum collaboration, reciprocity, and the preference for similarity: Developing an adaptive model of close relational functioning. Personal Relationships, 11, 135-160.

Colombi, C., Liebal, K., Tomasello, M., Young, G., Warneken, F., \& Rogers, S. (2009). Examining correlates of cooperation in autism: Imitation, joint attention, and understanding intentions. Autism, 13, 143-163.

Constantino, J. N., Davis, S. A., Todd, R. D., Schindler, M. K., Gross, M. M., \& Brophy, S. L. (2003). Validation of a brief quantitative measure of autistic traits: Comparison of the social responsiveness scale with the autism diagnostic interview-revised. Journal of Autism and Developmental Disorders, 33, 427-433.

Dahlgren, S. O., \& Trillingsgaard, A. (1996). Theory of mind in nonretarded children with autism and Asperger's syndrome. A research note. Journal of Child Psychology and Psychiatry, 37, 759-763.

Dunn, L. M., \& Dunn, L. M. (2004). Peabody picture vocabulary test (PPVT)-III-NL. Amsterdam: Hartcourt Test Publishers.

Eckerman, C. O., Davis, C. C., \& Didow, S. M. (1989). Toddlers' emerging ways of achieving social coordinations with a peer. Child Development, 60, 440-453.

Feldman, R., \& Greenbaum, C. W. (1997). Affect regulation and synchronicy in mother-infant play as precursors to the 
development of symbolic competence. Infant Mental Health Journal, 18, 4-23.

Gernsbacher, M. A. (2006). Toward a behavior of reciprocity. Journal of Developmental Processes, 1, 139-152.

Hadwin, J., Baron-Cohen, S., Howlin, P., \& Hill, K. (1997). Does teaching a theory of mind have an effect on social communication in children with autism. Journal of Autism and Developmental Disorders, 27, 519-537.

Happé, F. (1995). The role of age and verbal ability in the theory of mind task performance of subjects with autism. Child Development, 66, 843-855.

Happé, F., \& Frith, U. (2006). The weak coherence account: Detailfocussed cognitive style in autism spectrum disorders. Journal of Developmental Disorders, 36, 5-25.

Howes, C. (1988). Peer interaction of young children. Monographs of the Society for Research in Child Development, 53, 1-78.

Joseph, R. M., \& Tager-Flusberg, H. (2004). The relationship of theory of mind and executive functions to symptom type and severity in children with autism. Development and Psychopathology, 16, 137-155.

Kleinhans, N., Akshoomoff, N., \& Delis, D. C. (2005). Executive functions in autism and Asperger's disorder: Flexibility, fluency, and inhibition. Developmental Neuropsychology, 27, 379-401.

Klin, A., Saulnier, C., Sparrow, S., Cicchetti, D. V., Volkmar, F., \& Lord, C. (2007). Social and communication abilities and disabilities in higher functioning individuals with autism spectrum disorders. Journal of Autism and Developmental Disorders, 37, 788-793.

Komorita, S., Parks, C., \& Hubert, L. (1992). Reciprocity and the induction of cooperation in social dilemmas. Journal of Personality and Social Psychology, 62, 607-617.

Liebal, K., Colombi, C., Rogers, S. J., Warneken, F., \& Tomasello, M. (2008). Helping and cooperation in children with autism. Journal of Autism and Developmental Disorders, 38, 224-238.

Lord, C., Risi, S., Lambrecht, L., Cook, E. H., Leventhal, B. L., DiLavore, P. C., et al. (2000). The autism diagnostic observation schedule-generic: A standard measure of social and communication deficits associated with the spectrum of autism. Journal of Autism and Developmental Disorders, 30, 205-223.

Ozonoff, S., \& Miller, J. N. (1995). Teaching theory of mind: A new approach to social skills training for individuals with autism. Journal of Autism and Developmental Disorders, 25, 415-433.
Perez, S. M., \& Gauvain, M. (2005). The role of child emotionality in child behaviour and maternal instruction on planning taks. Social Development, 14, 250-272.

Ponnet, K. S., Buysse, A., Roeyers, H., \& De Corte, K. (2005). Empathic accuracy in adults with and without PDD during a dyadic conversation. Journal of Autism and Developmental Disorders, 35, 585-600.

Ponnet, K. S., Roeyers, H., Buysse, A., De Clercq, A., \& van der Heyden, E. (2004). Advanced-mind reading in adults with Asperger syndrome. Autism, 8, 249-266.

Russell, J., \& Hill, E. L. (2001). Action-monitoring and intention reporting in children with autism. Journal of Child Psychology and Psychiatry and Allied Disciplines, 42, 317-328.

Sally, D., \& Hill, E. L. (2006). the development of interpersonal strategy: Autism, theory- of-mind, cooperation and fairness. Journal of Economic Psychology, 27, 73-97.

Schatz, J., \& Hamdan-Allen, G. (2007). Effects of age and IQ on adaptive behaviour domains for children with autism. Journal of Autism and Developmental Disorders, 25, 51-60.

Schlichting, L. (2005). Peabody picture vocabulary test-III-NL. Lisse: Harcourt Test Publishers.

Senju, A., Southgate, V., White, S., \& Frith, U. (2009). Mindblind eyes: An absence of spontaneous theory of mind in Asperger syndrome. Science, 325, 883-885.

Tomasello, M., Carpenter, M., Call, J., Behne, T., \& Moll, H. (2005). Understanding and sharing intentions: The origins of cultural cognition. Behaviour and Brain Sciences, 28, 675-735.

Trevarthen, C., \& Aitken, K. J. (2001). Infant intersubjectivity: Research, theory, and clinical applications. Journal of Child Psychology and Psychiatry, 42, 3-48.

Warneken, F., \& Tomasello, M. (2006). Altruistic helping in human infants and young chimpanzees. Science, 311, 1301-1303.

Wimpory, D., Hobson, R., \& Nash, S. (2007). What facilitates social engagement in preschool children with autism? Journal of Autism and Developmental Disorders, 37, 564-573.

World Health Organization (WHO). (1992). The ICD-10 classification of mental and behavioural disorders; clinical descriptions and diagnostic guidelines. Geneva: World Health Organization.

Yirmiya, N., Erel, O., Shaked, M., \& Solomonica-Levi, D. (1998). Meta-analyses comparing theory of mind abilities of individuals with autism, individuals with mental retardation, and normally developing individuals. Psychological Bulletin, 124, 283-307. 